cionamento muito feliz, enquadrando tôdas as situações de maneira a tornar fácil e segura a decisão do administrador.

$\mathrm{E}$ assim foi. A edição de Curso de rotinas trabalhistas tem o mérito de, além de dar um embasamento necessário à análise trabalhista-administrativa, é acessível a todos, desde o mais simples dos auxiliares de pessoal até o mais notável dos jurisconsultos.
O leitor encontrará nas páginas desta publicação da LTr, todos os formulários oficiais, bem como sua forma correta de preenchimento. Não há dúvida de que êste ingrediente a mais vem de encontro ao enfoque da conversa mantida com José Serson, qual seja a de tornar claro o que a lei pode tornar escuro àqueles que não dominem a ciência jurídica.

LUÚS CÉSAR GONÇALVES DE ARAÚJO

\title{
Tapirapé: Tribo Tupi no Brasil Central
}

Por Herbert Baldus. São Paulo, Companhia Editôra Nacional, 1970. 511 p., il. (Brasiliana Editôra Nacional, 1970. 511 p., il. (Brasiliana Gigante, 17).

Herbert Baldus, etnólogo de formação européia, radicado no Brasil desde o comêço da década de 30 , é autor de uma série de livros sôbre os indígenas brasileiros. Seus trabalhos anteriores foram publicados na Revista do Museu Paulista, na Coleção Brasiliana, e alguns dêles saíram publicados, também, nos Estados Unidos e Europa. Dentre êles, podemos citar: Ensaios de etnologia brasileira, Manual bibliográfico de estudos brasileiros $\mathrm{e}$ Dicionário de etnologia e sociologia.

Tapirapé: tribo tupi no Brasil central é uma obra que descreve minuciosamente a cultura tapirapé, comparada, nos seus distintivos, com as culturas das tribos vizinhas e outras tribos tupis. O material básico para sua elaboração foi colhido pelo próprio autor nas duas visitas que fêz aos tapirapés, a primeira em 1935 e a segunda em 1947.

Afirma Baldus que êles são o povo mais alegre que já conheceu. Assustam-se com facilidade, mas com a mesma facilidade voltam a sorrir. Embora não dêem muita importância aos instrumentos musicais, gostam do canto. Amam muito seus filhos, sendo bastante afetuosos para com êles. A infância, entretanto, é curta. As crianças já ajudam os pais no trabalho, não havendo muito tem- po para jogos e brincadeiras infantis. Há, entretanto, um fenômeno curioso: a instituiçäo da criança preferida. Esta seria uma espécie de mascote da tribo. Diferencia-se das outras crianças por não ter que ajudar no trabalho, estar sempre bem arrumada e viver na companhia dos homens mais importantes da tribo. E seu dever ser amável com todos.

Quanto à religião, revelam originalidade em relação às outras tribos. Acreditam que as fôrças sobrenaturais estão localizadas horizontalmente nas extremidades da terra habitada pelos homens e não por cima ou por baixo dêles. Acreditam, também, num mundo subterrâneo, tendo os antepassados saído do centro da terra.

O universo tapirapé é dualista: esta concepção surge da idéia da existência de dois casais dando origem à tribo, como na sua divisão em metades cerimoniais, ou seja, a existência de fenômenos duais nas festas e ritos. Como exemplo, temos os tata-upaua, ou grupos de comer: em festas cspeciais, a tribo se divide em dois grandes grupos, para o consumo de alimentos. Cada uma dessas. metades possui chefes distintos, que teòricamente se igualam em poder. 
A questão da existência ou não de uma forte autoridade central entre os tapirapés é muito discutida. Baldus acha que ela fica demonstrada, entre outras coisas, pela fôrça de integração que o chefe exerce sôbre a população da aldeia, não permitindo a separação de seus membros. Kamairahó, o chefe tapirapé, por ocasião da primeira visita de Baldus, estabelecera o padrão de comportamento (behaviour pattern) da tribo, através das suas atitudes e presidindo a vida cotidiana da aldeia. Os chefes estão parcialmente isentos das abstenções alimentares, tarefas e trabalhos. São os únicos que andam vestidos.

Por sua vez, a base da vida material dos tapirapés é a pesca e a lavoura, embora também colham frutos selvagens e cacem. Estas atividades estão ligadas a uma rígida divisão sexual do trabalho: o homem vai à busca do sustento, e a mulher se ocupa das tarefas caseiras, do fabrico das panelas de barro e de tudo que é feito com o pilão ou por fiação. Devido à exclusividade das atribuições de cada sexo, há uma grande interdependência entre ambos, fazendo com que os homens solteiros sejam marginalizados socialmente. Sem mulher, não têm o que comer, rêde para dormir etc., enfim, não têm acesso a nada que seja atribuição exclusiva da mulher, vivendo de caridade.

Os tapirapés são geralmente monogâmicos. Admitem, normalmente, o divórcio. Há grande liberdade nos costumes, nas relações pessoais. As relações sexuais anteriores ao casamento são permitidas.

Quanto à organização social, foi difícil para Baldus compreender sua estrutura. Isso se deveu aos problemas com a língua, à exigüidade de tempo, mas, principalmente, às consequiências das epidemias despovoantes que afetaram o sistema de parentesco. Por isso, certos problemas de importância, como os relativos à endogamia e à exogamia, não puderam ser esclarecidos. Outros pontos, entretanto, da estrutura social ficaram claros: a descendência tapirapé e a existência de uma organização tripartida da tribo. Quanto à primeira, os filhos sucedem por linha paterna, e as filhas, por linha materna. Quanto à segunda, manifesta-se na divisão dos homens em três grupos, que visam a contribuir para a aquisição do sustento, por atividades acompanhadas de danças e banquetes.

O principal problema levantado na obra é a decadência física e cultural dos tapirapés, devida, principalmente, ao contato com os brancos. Se bem que a extinção física seja causada, em grande parte, pelo modo de vida dos tapirapés, isto é, pelos seus hábitos alimentares, de sono, de tratamento de doenças etc., a disseminação das doenças trazidas pelos brancos é seu principal agente. Por sua vez, o contato com a cultura ocidental desencadeia o processo das perdas culturais, isto é, a perda dos valôres e costumes próprios aos tapirapés, que não resistem ao impacto de uma cultura superior. Frente a essa fôrça desintegradora, êles não transformaram ou substituíram seus valôres e costumes por outros, que pudessem constituir a base de uma nova configuração cultural. A cultura tapirapé vai desaparecendo lentamente, à medida que se acelera o seu processo de aculturação.

Baldus descreve muito bem a coexistência de valôres e costumes: "... Colheres de metal ao lado de conchas e cuias; miçangas ao lado de sementes; uma peça de nossa roupa junto à pintura do corpo; cachimbo de fornilho ereto à moda dos brancos, ao lado dos simples tubo de fumar; Jesus Cristo identificado com o personagem que, na mitologia, aparece como dono de grandes corpos e objetos de ferro, como capitão, espôso e pai". Confirmando esta situação, encontramos outros exemplos, no comportamento que os membros da tribo passaram a ter: em 1947, muitas mulheres, que em 1935 andavam completamente nuas, passaram a se vestir na presença de brancos. Perdeu-se, também, o sentimento de hospitalidade, que fôra muito acentuado. Em 1953, ninguém mais dizia ser pagé; as abstenções alimentares, antes rigorosamente observadas, foram suspensas; de- 
sapareceram os Xamãs, protagonistas da religião tapirapé, protetores da tribo contra perigos sobrenaturais e sem os quais não havia esperança de sobrevivência. Poucos estavam dispostos a aprender $\circ$ trançado de cestos, técnica bem desenvolvida pelos antecessores. E, o que é mais importante, conforme se acelera êste processo, os tapirapés tornam-se acessíveis a novas doutrinas, principalmente à catequese.

O livro é fartamente ilustrado, com fotografias e desenhos de objetos, instrumentos, pessoas, danças, festas e cenas da vida cotidiana, o que ajuda a dar uma imagem mais completa desta tribo do Brasil Central. O trabalho é um documento precioso para o conhecimento etnológico do indígena brasileiro, servindo como achegas aos estudos das ciências humanas.

A obra traz, em apêndice, um estudo do professor Emílio Willens, Caracteristicas antropométricas dos tapirapés.

MARISA SAENZ LEME

\section{A Pesquisa Histórica no Brasil}

Por José Honório Rodrigues. São Paulo, Companhia Editôra Nacional, 1969. 283 p.

José Honório Rodrigues reformulou seu livro A pesquisa histórica no Brasil $\left(1 .^{\mathrm{a}}\right.$ edição em 1952), preocupado em enfrentar "novas definições muito difíceis" e em "atender ao espírito da mocidade estudiosa". Por isso, acrescentou-lhe alguns capítulos e modificou-lhe as noções preliminares.

O autor dá informações preciosas aos pesquisadores iniciantes, alertando-os das dificuldades no contato e manejo dos documentos. Além disso, mostra que, infelizmente, o Estado não se interessa em recolher e preservar o material histórico; daí ser fraco o apoio às eventuais tentativas de aperfeiçoamento $\mathrm{e}$ renovação das instituições que se dedicam à pesquisa. Por sua vez, os órgãos arquivísticos que, de maneira geral, mostraram-se negligentes no trabalho de preservação do material primário, muitas vêzes não puderam agir melhor por falta de recursos.

Apesar dessas dificuldades, a gestão de José Honório Rodrigues como Diretor do Arquivo Nacional (assumiu a direção em 1958), possibilitou certa ação positiva. Nessa época, êle levanta a idéia da criação de um Instituto Nacional de Pesquisa Histórica, que teria a finalidade de preencher as lacunas de nossas fontes de trabalho, assim como a aperfeiçoamento dos órgãos já existentes. Parece-lhe imprescindível a criação de um organismo dessa natureza, que planejasse a organização dos instrumentos do trabalho histórico, recolhendo e inventariando papéis referentes ao Brasil, localizados no país ou no exterior.

Depois dessas colocações, o autor acentua que "a pesquisa histórica é a descoberta cuidadosa, exaustiva e diligente de novos fatos históricos, a busca de documentos, que provam a existência dos mesmos, permita sua incorporação ao escrito histórico ou a revisão e interpretação nova da história", e que "a pesquisa deve ser definida em têrmos de serviço público e deve ser sistematizada, planejada e ordenada". O desenvolvimento da pesquisa histórica e o aperfeiçoamento da historiografia são, para o autor, resultados da preservação e do contrôle documentais. Por isso, sua atenção se dirige para o estado em que se encontram nossos órgãos arquivísti$\cos$, públicos ou privados. Um capítulo especial é dedicado ao exame das bibliotecas e arquivos, nacionais ou estrangeiros. O livro contém uma relação sistematizada e ordenada dessas instituições. 